This is an electronic reprint of the original article. This reprint may differ from the original in pagination and typographic detail.

Author(s): Friesen, Andrew; Lane, Andrew; Galloway, Shaun; Stanley, Damian; Nevill, Alan; Ruiz, Montse C.

Title: $\quad$ Coach-athlete perceived congruence between actual and desired emotions in karate competition and training

Year: $\quad 2018$

Version:

Please cite the original version:

Friesen, A., Lane, A., Galloway, S., Stanley, D., Nevill, A., \& Ruiz, M. C. (2018). Coachathlete perceived congruence between actual and desired emotions in karate competition and training. Journal of Applied Sport Psychology, 30(3), 288-299. https://doi.org/10.1080/10413200.2017.1388302

All material supplied via JYX is protected by copyright and other intellectual property rights, and duplication or sale of all or part of any of the repository collections is not permitted, except that material may be duplicated by you for your research use or educational purposes in electronic or print form. You must obtain permission for any other use. Electronic or print copies may not be offered, whether for sale or otherwise to anyone who is not an authorised user. 


\section{Coach-Athlete Perceived Congruence Between Actual and Desired Emotions in Karate Competition and Training}

\section{Andrew Friesen, Andrew Lane, Shaun Galloway, Damian Stanley, Alan Nevill} \& Montse C. Ruiz

To cite this article: Andrew Friesen, Andrew Lane, Shaun Galloway, Damian Stanley, Alan Nevill \& Montse C. Ruiz (2017): Coach-Athlete Perceived Congruence Between Actual and Desired Emotions in Karate Competition and Training, Journal of Applied Sport Psychology, DOI: 10.1080/10413200.2017.1388302

To link to this article: http://dx.doi.org/10.1080/10413200.2017.1388302

Accepted author version posted online: 10

Oct 2017.

Submit your article to this journal $\widetilde{\pi}$

View related articles $\sqsubset$

View Crossmark data 
Coach-Athlete Perceived Congruence Between Actual and Desired Emotions in Karate

Competition and Training

Andrew Friesen ${ }^{1}$, Andrew Lane ${ }^{1}$, Shaun Galloway ${ }^{1}$, Damian Stanley ${ }^{2}$, Alan Nevill ${ }^{3}$, Montse C. Ruiz $^{4}$

${ }^{1}$ University of Wolverhampton

${ }^{2}$ Coventry University

${ }^{3}$ University of Wolverhampton

${ }^{4}$ University of Jyvaskyla

*Correspondence to Andrew Friesen, University of Wolverhampton, Gorway Road, Walsall, UK. Email: apfriesen@gmail.com

\begin{abstract}
Coaches can help athletes regulate emotions but would benefit from tools that help them accurately perceive athletes' emotions. In the present study, we investigated the use of video recorded performances to compare three martial artists' ratings of desired and actual emotions with their coach's ratings. Results show how desired emotions progressively fluctuated throughout competition. Furthermore, desired and actual emotions differed between training and performance contexts. Finally, we report correlations between performance and perceived congruence in desired and actual emotions. Cumulatively, results offer support for the videoassisted recall of emotions as an intervention tool in developing emotion regulation abilities.
\end{abstract}




\section{ACCEPTED MANUSCRIPT}

Research indicates that martial artists experience a wide range of emotions before and during competition (Cerin \& Barnett, 2011; Robazza, Bortoli, \& Hanin, 2004; Ruiz \& Hanin, 2004, 2011; Terry \& Slade, 1995) and that these emotions can strongly influence performance (e.g., Chapman, Lane, Brierley, \& Terry, 1997; Devonport, Lane, \& Hanin, 2005). Therefore, the ability to regulate emotions becomes an important mental skill for martial artists to learn, develop and master. Emotion regulation refers to efforts to change one's feelings in the pursuit of hedonic and instrumental goals (Tamir, Mitchell, \& Gross, 2008). Emotion-performance relationships tend to be very individual (Hanin, 2010) and so there is not a common emotional profile that could be used as a standard for emotion regulation. Effective emotion regulation, however, involves the deliberate attainment of a desired emotional state (Gross, 2015), thus, it is crucial to identify the discrepancies between the emotions that athletes actually experience, and those that they would desire to experience. Athletes, and martial artists in particular, use a variety of strategies to regulate their emotions including listening to music, self-talk, talking to others, and imagery (Lane, Beedie, Jones, Uphill, \& Devonport, 2012; Massey, Meyer, \& Naylor, 2015). However, not all emotion regulation is self-driven or initiated by the athlete. Athletes' emotions can be regulated by others (e.g., teammates, coaches, referees), a process labelled interpersonal emotion regulation (e.g., Friesen et al., 2013; Friesen, Devonport, \& Lane, 2016; Niven, Totterdell, \& Holman, 2009). Particularly, coaches can influence athletes' emotions either directly via persuasive techniques that aim to change the athlete's appraisals or indirectly through self-management and emotion contagion (Friesen et al., 2013). The aim of the present study is to investigate differences between desired emotions and actual emotions (i.e., emotions actually experienced) by martial artists, examining the perspectives of the coach and the athlete. 


\section{ACCEPTED MANUSCRIPT}

Athletes typically regulate their emotions to achieve certain goals (Lane, Beedie, Devonport, \& Stanley, 2011). This type of instrumental emotion regulation is therefore dependent on the setting that the athlete is exposed to (Campo, et al., 2016; Tamir, 2011). Typically, the goal in competition is to defeat your opponent or achieve personal best performances where the perceived or actual consequences of failure are usually high. Conversely, within a training setting, goals are more learning-focused, intended to practice skills and learn new techniques, and failure is seen as a normal part of learning. Not surprisingly, research indicates differences in emotional experiences between training and competition (Nicholls, Levy, Grice, \& Polman, 2009; Terry \& Lane, 2000).

Whether a coach should attempt to regulate an athlete's emotion is guided by empathic discrepancies between desired emotions (i.e., what they want their athlete to feel) and actual emotions (i.e., what they perceive their athlete to feel) (cf. Zaki \& Williams, 2013). For example, if a coach perceives her athlete to be feeling anxious and believes that this feeling is detrimental to performance, the coach will likely attempt to help the athlete reduce the anxiety. In this case, the perception of emotions and awareness or knowledge about their functional impact on performance is crucial. However, the coach does not have access to the athlete's inner feelings and therefore can only infer their athletes' feelings from observing expressions and using empathy (Petrides, Furnham, \& Mavroveli, 2007). Following temporal models of emotion regulation (e.g., Gross, 2015), emotion perception represents the starting point for consequential regulation, with inaccurate perceptions leading to emotion regulation failure. Likewise, the ability to perceive another person's emotional states represents an important part in the interpersonal emotion regulation process (Dixon-Gordon, Bernecker, \& Christensen, 2015; 


\section{ACCEPTED MANUSCRIPT}

Losoya \& Eisenberg, 2001). That is, before emotion regulation strategies can be deployed, the coach needs to accurately perceive how his or her athlete is feeling, and importantly, wants to feel. Regarding this process, the individual relationships between emotion and performance presents a challenge for a coach. Consider an example of two athletes feeling energetic before a contest. One athlete might want to feel even more energetic, whereas the other athlete might wish to feel calmer. In such instances, the coach would need to be able to perceive a discrepancy between how each athlete is currently feeling and how the athlete wants to feel, to help determine appropriate emotion regulation strategies for each athlete.

Assessing emotions in sport performances has some limitations based on the nature of emotion and the confines of research. While a complete discussion of these limitations is beyond the remit of the current study (see Lane \& Terry, 2016), there is a need for new methods to be developed based on the following emotion-performance characteristics. The first is that emotions are transitory in nature (Cerin, Szabo, Hunt, \& Williams, 2000; Hanin, 2010). What and how intensively an athlete feels can vary throughout a performance depending on the athlete's appraisal of the interaction with the environment (Lazarus, 2000). As matches progress and results unfold, the emotions athletes might desire to feel will change to coincide with new emergent performance goals. For example, an athlete might desire to feel very aggressive at the start of a match, but if the athlete becomes injured part-way through, the athlete might desire to not feel so aggressive in order to keep from exacerbating the injury. Methods that capture this dynamic nature can be preferable to assessing emotions only prior to competition (e.g., Cerin \& Barrett, 2011; Jones, Lane, Bray, Uphill, \& Catlin, 2005; Lane et al., 2010). 


\section{ACCEPTED MANUSCRIPT}

Secondly, not only are the type and the intensity of emotions important to assess, but Thomas, Picknell, and Hanton (2011) has also demonstrated that measuring the frequency of emotional changes throughout a performance can provide a more accurate description of an athlete's experiences. Therefore, a method that can record both intensity and frequency is warranted (Martinent, Campo, \& Ferrand, 2012). Thirdly, Terry (1995) argued that while the pre-competition phase represents a practical opportunity for a sport psychologist to intervene or consult with athletes, coaches are in the unique position where they have multiple opportunities to regulate athletes' emotions throughout competition (Martinent, Ledos, Ferrand, Campo, \& Nicolas, 2015). Therefore, assessing methods that utilize this advantage is important for sports psychology research.

Many researchers have argued that video recording is an effective practical tool for assessing emotional states experienced during competition (Bertram, Marteniuk, \& Guadagnoli, 2007; Ives, Straub, \& Shelley, 2002; Martinent et al., 2015). Previous research examining optimal emotional states for performance has tended to rely on past recollections of emotional events whereby athletes identify their feelings at a specific point in time (e.g., Dewar \& Kavussanu, 2011; Nicholls, Polman, \& Levy, 2011). With the aid of video replay, participants view performance footage and describe or rate emotions experienced in real-time (cf. Campo et al., 2016; Martinent et al., 2015). This type of method to study interpersonal emotion regulation has been used in other areas of psychology to good effect (e.g., Butler, Hollenstein, Shoham, \& Rohrbaugh, 2012; Parkinson \& Simons, 2012).

In sum, previous research examining emotion regulation has taken an athletes' perspective mainly focusing on the specific strategies used by them in order to successfully 


\section{ACCEPTED MANUSCRIPT}

pursue instrumental goals. The role of others, and that of the coach in particular, has typically not been considered in emotion regulation. The perception of emotions and knowledge about the functional impact on performance is crucial for effective emotion regulation. Exploring the discrepancies between athletes' actual emotions and desired (optimal) emotions both from an athlete's and a coach's perspective would have important implications for emotion regulation. The aim of the present study was to investigate differences between desired emotions and actual emotions of martial artists, examining the perspectives of the coach and the athlete. We hypothesised that there will be differences in desired emotions between training and competition settings (hypothesis 1); there will be fluctuations in desired emotions throughout competition (hypothesis 2); and there will be significant correlations between perceived performance and the extent to which desired and actual emotions were congruent (hypothesis 3).

\section{Method}

\section{Participants}

The coach was a 40 year old male with 24 years of experience coaching national and international level athletes in karate. Three of his athletes participated in this case study and their descriptive profiles are presented in Table 1.

\section{Measures}

Emotions. We developed an instrument comprised of two questions asking, "Rate how you wanted to feel at the start of the fight (or training session)" and, "Rate how you were actually feeling at that time." Each question included nine items representing nine distinct emotions (i.e., "happy," “angry," "calm," "downhearted," "energetic," "still," "sluggish," "enthusiastic," "anxious"). These emotions represent the four quadrants of Russell's (1980) 


\section{ACCEPTED MANUSCRIPT}

circumplex model of emotions that distinguishes emotions along a valence continuum and an arousal continuum. Each item was rated on a 7-point Likert scale ranging from 1 (not at all) to 7 (extremely). After answering these two questions, participants were given the following instructions: "Now start watching the video and every time any emotion changed during the session, pause the video, enter the time from the clip in the time column and rate all of your emotions, and your performance at that point in the session." Space was provided on the instrument for the participants to respond and rate each of the nine emotions for every time they paused the video.

Performance. At each moment when participants reported their emotions, they also reported an overall performance score based on their subjective perceptions (Terry, 1995). This was rated on a 7-point Likert scale ranging from 1 (poor performance) to 7 (extremely good performance).

\section{Procedure}

Following institutional ethical approval of the study, the coach and three of his athletes from a martial arts club were approached to participate in the study. The observational nature and procedures of the study were explained to the participants and written consent to participate was obtained. Participants then provided demographic information.

The coach was tasked with choosing and filming one practice session and one competitive tournament match for each athlete. Each training session video lasted 90 minutes with one hour being supervised by the coach. The footage that was analysed for training included technical, tactical and sparring aspects. Competition videos varied in length in accordance with the length of the matches. For Athlete 1, the competition consisted of four fights, each a 


\section{ACCEPTED MANUSCRIPT}

maximum duration of 3 minutes. He won all four fights, with the fourth being an event final. For Athlete 2, the tournament video consisted of three fights, each a maximum duration of 3 minutes, with her winning all three. For Athlete 3, the tournament video was of two fights. He was eliminated from the contest after losing the second fight.

Within a week of the sessions being recorded, participants met individually with a member of the research team to watch the videos. Athlete participants used the instrument to report the emotions they had: (a) desired to feel, and (b) actually felt, in the hour before their training session and competitive match. The athlete participants then watched their respective videos. When watching the videos, any time the athlete remembered experiencing a specific change in emotions, the athlete paused the video. Consistent with the approach used by Martinent et al. (2012) for assessing emotions during performance, the researcher noted the time at which the athlete paused the video, and recorded the athlete's rating of desired and actual emotions experienced as well as performance using the instrument.

A similar procedure was then undertaken with the coach. The coach and researcher watched the same videos and the researcher paused the videos at every time point the athlete had paused the video. The coach then reported what he perceived the athlete's desired and actual emotions were at that time using the instrument. The coach also provided subjective ratings of performance at each pause.

\section{Data analysis}

To answer our research questions, we first examined whether athletes and coach desired for the athlete to experience different emotions between training and competition contexts. We used a repeated measures MANOVA to examine potential differences for the athletes collectively as 


\section{ACCEPTED MANUSCRIPT}

well as for the coach in the two conditions (i.e., training and competition). For our second question, we separated desired emotion scores by the fight round they were recorded in order to see whether desired emotions fluctuated throughout the course of competition. We examined progressive changes using a repeated measures MANOVA. Finally, we analysed whether congruence between desired emotions and those that were actually experienced predicted ratings of performance. We subtracted scores for desired emotions from scores from actual emotions creating a new variable (labelled "emotion congruence"). We then correlated emotion congruence with perceived subjective performance scores. We did this for each of the nine emotions for both the athletes and the coach using Pearson correlations.

\section{Results}

In total, 90 time-point recordings ( $N=56$ competition; $N=34$ training) were collected and analysed (see Table 2).

We analysed whether the desired emotions differed across training and competition contexts (hypothesis 1). The interaction between athletes' collective emotion intensities indicated significant differences between these two contexts. (Wilks Lambda $=0.654 ; F[8,81]=5.353, \mathrm{p}<$ .01 , see Figure 1). There were higher intensity discrepancies for anger and enthusiasm, with athletes reporting higher intensities scores for competition. Conversely, athletes reported a desire to feel lower intensities for downheartedness and sluggishness in competition. Responses from the coach also indicated a significant difference between desired emotions across training and competition contexts (Wilks Lambda $=0.033 ; F[8,80]=288.5, \mathrm{p}<.01$, see Figure 2 ). There were higher discrepancies for anxiety and calmness, with higher intensity scores desired for 


\section{ACCEPTED MANUSCRIPT}

competition. And, similarly to the athletes, the coach reported lower desired intensities for downheartedness and sluggishness in competition.

We also sought to determine whether athletes' desired emotions fluctuate throughout the course of competition (hypothesis 2). Using rounds as time comparables, a repeated measures multivariate test revealed significant differences throughout the course of competition for all the athletes $($ Wilks Lambda $=0.424 ; F[24,122.4]=1.75, \mathrm{p}<.05)$. See Figure 3 .

We analysed the extent to which discrepancies between athletes' actual and desired emotions correlated with perceived performance (hypothesis 3). Pearson correlations between emotion congruence and performance were significant for all emotions. Similarly, we analysed the extent to which discrepancies between the coach's perceived actual and desired athlete emotions correlated with his perceived performance. Pearson correlations between emotion congruence and performance were significant for all emotions, indicating that greater congruency between the desired and actual emotion was positively correlated with better perceived performance (see Table 3).

\section{Discussion}

The aim of the present study was to investigate differences between desired emotions and actual emotions experienced by martial artists. We documented the differences in desired and actual emotions across contexts (i.e., training vs. competition). We further found the emotions athletes desired to feel both as reported by themselves and the coach fluctuated throughout the course of competition. Finally, we found that there were significant correlations between desired and actual emotion congruence and perceived performance for most of the emotions. That is, 


\section{ACCEPTED MANUSCRIPT}

higher congruence between what the athletes felt and what they wanted to feel was associated with higher ratings of performance.

Results indicated that the athletes in this study desired to feel different emotions at specific points in time in competition. Specifically, there was a progressive increase in high energy feelings (i.e., anger, energetic, and anxiety) as the athletes progressed through their competitive rounds. This is consistent with past research that suggests that optimal karate performance can be achieved or maintained with high levels of unpleasant emotions (cf: Ruiz \& Hanin, 2004; 2011). The progressive increase in energizing emotions could be a tactical strategy. Similar to training contexts, early rounds in competition might be devoted to achieving information-gathering goals (i.e., opponents "feeling" each other out) to learn about the other's fight style or tactics. As competition progresses, the goals can shift from being primarily focused on information-gathering to including action-implementation. This would then be reflected in the athlete's desired emotional state whereby the athlete would desire energizing emotions to help facilitate quick and powerful movements (Perkins, Wilson, \& Kerr, 2001; Tod, Iredale, \& Gill, 2003). An important implication for coaches and athletes then would be to prepare emotion regulation strategies that can be effectively employed during competition with minimal effort.

The athletes in this study presented significantly different desired emotion profiles between training and competition contexts. This finding supports past research that has highlighted these discrepancies (cf. Nicholls et al., 2009; Terry \& Lane, 2000). Whilst sports psychology practitioners often encourage athletes and coaches to practice in training the psychological skills that they intend to employ in competition, our results highlight that the training context itself represents a performance setting with its own particular goals. 


\section{ACCEPTED MANUSCRIPT}

Unsurprisingly, both athletes and coach wanted reported desired intensities for downheartedness and sluggishness to be nearly zero. This is to be expected as both emotions are associated with physical exhaustion which would not be perceived as instrumental to martial arts (Robazza et al., 2004). The athletes reported the desire to feel higher levels of anger, whereas the coach desired higher levels of anxiety in competition. Both of these emotions have been reported as potentially useful for performance effects in martial arts (Ruiz \& Hanin, 2004, 2011). Research on psychological skills usage indicates that athletes are more prone to use psychological skills in competition rather than practice settings (Lane, Harwood, Terry, \& Karageorghis, 2003; Thomas, Murphy, \& Hardy, 1999). Our results suggest that sports psychology practitioners work with coaches and athletes to develop effective psychological skills that might aid in achieving training session goals.

Findings from the current study also suggest that perceived performance is related to whether or not athletes are feeling how they desire to feel in competition. That is, participants believed that they were performing particularly well when there was minimal discrepancy between desired emotions and those that were actually experienced. The extent to which athletes feel how they desire to feel in competition can be indicative of their attempts to regulate emotions (Gross, 2015; Lane et al., 2012; Tamir, et al., 2008). That is, if an athlete is feeling how

they desire to feel, they can be considered as successful in regulating their emotions. Conversely, if there is a large discrepancy between desired emotions and actual emotions, this would suggest a failure to regulate emotions. The results from our study suggest that athletes will typically be pleased with their performance when they are also successful at regulating their emotions. 


\section{ACCEPTED MANUSCRIPT}

Another applied recommendation from the present study is that video recording offers a practical way of accessing emotional states experienced during competition and training (cf: Bertram et al., 2007; Ives et al. 2002; Martinent et al., 2015). Previous research to identify optimal emotional states for performance has tended to rely on past recollections of emotional events whereby athletes identify their feelings at a specific point in time (e.g., Robazza et al., 2004), including their best or worst performances (Hanin, 2010) without the use of visual prompts. We suggest that recording an athlete's performance is not only relatively straightforward with modern technology, but also offers a useful approach to help identify differences between coach and athlete perceptions of performance or situations experienced. Raising self-awareness should act as a trigger to initiate self-regulatory processes to reduce discrepancies between current and optimal emotional states (Carver, 2004). Video recording also allows coaches to collect data on their athletes in genuine performance settings. Research contrasting accuracy of interpersonal perceptions of emotions has often relied on data collection from laboratories where the emotions that participants experience do not necessarily resemble those experienced in natural settings (Gross, 2010). Video recordings circumvent this limitations aiding to its potential as a practical training tool.

The current study has a number of limitations. The first limitation is a very small sample size. The study, however, contrasted athletes' actual and desired emotions both from an athletes and coaches perspective in a total of 90 time-point recordings which allowed for a sound analysis of such discrepancies. The authors were interested in developing a strategy to help athletes and coaches monitor emotion perceptions (both intra- and interpersonal) which represents the precursor to emotion regulation (Lane et al., 2012). Secondly, with the addition of measures of 


\section{ACCEPTED MANUSCRIPT}

objective performance, there might have been the opportunity to extend the implications of the study pertaining to emotion-performance relationships. Future research should address these limitations and examine whether the effects remain comparable. With video-assisted recall becoming a useful tool in emotion regulation research, it would be prudent for future research to include these procedures in experiments that test the efficacy and effectiveness of emotion regulation strategies. Given that many sports already include videos as part of their technical and tactical debriefs, there is opportunity for psychological and emotion regulation skills to be included within such debriefs with minimal additional effort. 


\section{ACCEPTED MANUSCRIPT}

\section{References}

Bertram, C. P., Marteniuk, R. G., \& Guadagnoli, M. A. (2007). On the use and misuse of video analysis. International Journal of Sports Science \& Coaching, 2, 37--46. doi:10.1260/174795407789705406

Butler, E. A., Hollenstein, T., Shoham, V., \& Rohrbaugh, M. J. (2014). A dynamic state-space analysis of interpersonal emotion regulation in couples who smoke. Journal of Social and Personal Relationships, 31(7), 907--927. doi:10.1177/0265407513508732

Campo, M., Sanchez, X., Ferrand, C., Rosnet, E., Friesen, A., \& Lane, A. M. (2016). Interpersonal emotion regulation in team sport: Mechanisms and reasons to regulate teammates' emotions examined. International Journal of Sport and Exercise Psychology, 1--16. doi: 10.1080/1612197X.2015.1114501

Carver, C. S. (2004). Self-regulation of action and affect. In R. F. Baumeister, \& K. D. Vohs (Eds.), Handbook of self-regulation: Research, theory and applications (pp. 13--39). New York, NY: Guilford Press.

Cerin, E. E., \& Barnett, A. (2011). Mechanisms linking affective reactions to competition-related and competition-extraneous concerns in male martial artists. Scandinavian Journal of Medicine \& Science in Sports, 21, 700--712. doi:10.1111/j.1600-0838.2009.01072.x

Cerin, E., Szabo, A., Hunt, N., \& Williams, C. (2000). Temporal patterning of competitive emotions: A critical review. Journal of Sports Sciences, 18(8), 605--626. doi:10.1080/02640410050082314 


\section{ACCEPTED MANUSCRIPT}

Chapman, C., Lane, A. M., Brierley, J., \& Terry, P. C. (1997). Anxiety, self-confidence and performance in tae kwon-do. Perceptual and Motor Skills, 85, 1275--1278. doi:10.2466/pms.1997.85.3f.1275

Dewar, A. J., \& Kavussanu, M. (2011). Achievement goals and emotions in golf: The mediating and moderating role of perceived performance. Psychology of Sport and Exercise, 12(5), 525--532. doi:10.1016/j.psychsport.2011.05.005

Devonport, T. J., Lane, A. M., \& Hanin, Y. (2005). Emotional states of athletes prior to performance induced injury. Journal of Sports Science \& Medicine, 4, 382--394.

Dixon-Gordon, K. L., Bernecker, S. L., \& Christensen, K. (2015). Recent innovations in the field of interpersonal emotion regulation. Current Opinion in Psychology, 3, 36-42. doi:10.1016/j.copsyc.2015.02.001

Friesen, A. P., Devonport, T. J., \& Lane, A. M. (2016). Beyond the technical: The role of emotion regulation in lacrosse officiating. Journal of Sports Sciences, 1--8. doi:10.1080/02640414.2016.1180419

Friesen, A. P., Lane, A. M., Devonport, T. J., Sellars, C. N., Stanley, D. M., \& Beedie, C. J. (2013). Emotion in sport: Considering interpersonal regulation strategies. International Review of Sport and Exercise Psychology. doi:10.1080/1750984X.2012.742921

Gross, J. J. (2015). Emotion regulation: Current status and future prospects. Psychological Inquiry, 26, 1--26. doi:10.1080/1047840X.2014.940781

Hanin, Y. L. (2010). Coping with anxiety in sport. In A. R. Nicholls (Ed.), Coping in sport: Theory, methods, and related constructs (pp. 159--175). Hauppauge, NY: Nova Science. 


\section{ACCEPTED MANUSCRIPT}

Ives, J. C., Straub, W. F., \& Shelley, G. A. (2002). Enhancing athletic performance using digital video in consulting. Journal of Applied Sport Psychology, 14, 237-245. doi:10.1080/10413200290103527

Jones, M. V., Lane, A. M., Bray, S. R., Uphill, M., \& Catlin, J. (2005). Development and validation of the Sport Emotion Questionnaire. Journal of Sport and Exercise Psychology, 27, 407--431. doi:10.1123/jsep.27.4.407

Lane, A. M., Beedie, C. J., Devonport, T. J. \& Stanley, D. M. (2011). Instrumental emotion regulation in sport: Relationships between beliefs about emotion and emotion regulation strategies used by athletes. Scandinavian Journal of Medicine \& Science in Sports, 21, e445-e451. doi:10.1111/j.1600-0838.2011.01364.x

Lane, A. M., Beedie, C. J., Jones, M. V., Uphill, M., \& Devonport, T. J. (2012). The BASES expert statement on emotion regulation in sport. Journal of Sports Sciences, 30, 1189-1195. doi:10.1080/02640414.2012.693621.

Lane, A. M., Devonport, T. J., Soos, I., Karsai, I., Leibinger, E., \& Hamar, P. (2010). Emotional intelligence and emotions associated with optimal and dysfunctional athletic performance. Journal of Sports Science \& Medicine, 9(3), 388--392.

Lane, A. M., Harwood, C., Terry, P. C., \& Karageorghis, C. I. (2004). Confirmatory factor analysis of the Test of Performance Strategies (TOPS) among adolescent athletes. Journal of Sports Sciences, 22(9), 803--812. doi:10.1080/02640410410001716689

Lane, A. M., \& Terry, P. C. (2016). Online mood profiling and self-regulation of affective responses. In R. Schinke, K. McGannon \& B. Smith, (Eds). International handbook of sport psychology (pp. 324--333). London: Routledge. 


\section{ACCEPTED MANUSCRIPT}

Lazarus, R. S. (2000). How emotions influence performance in competitive sports. The Sport Psychologist, 14, 229--252.

Losoya, S. H., \& Eisenberg, N. (2001). Affective empathy. In J. A. Hall \& F. J. Bernieri (Eds.), Interpersonal sensitivity: Theory and measurement (pp. 21-43). Mahwah, NJ: Erlbaum.

Martinent, G., Campo,M., \& Ferrand, C. (2012). A descriptive study of emotional process during competition: Nature, frequency, direction, duration and co-occurrence of discrete emotions. Psychology of Sport \& Exercise, 13, 142--151. doi:10.1016/j.psychsport.2011.10.006

Martinent, G., Ledos, S., Ferrand, C., Campo, M., \& Nicolas, M. (2015). Athletes' regulation of emotions experienced during competition: A naturalistic video-assisted study. Sport, Exercise, and Performance Psychology, 4(3), 188--205. doi:10.1037/spy0000037

Massey, W. V., Meyer, B. B., \& Naylor, A. H. (2015). Self-Regulation Strategies in Mixed Martial Arts. Journal of Sport Behavior, 38(2), 192--211.

Nicholls, A. R., Levy, A. R., Grice, A., \& Polman, R. C. J. (2009). Stress appraisals, coping, and coping effectiveness among international cross-country runners during training and competition. European Journal of Sport Science, 9, 285--293. doi:10.1080/17461390902836049

Nicholls, A. R., Polman, R. C., \& Levy, A. R. (2012). A path analysis of stress appraisals, emotions, coping, and performance satisfaction among athletes. Psychology of Sport and Exercise, 13(3), 263--270. doi:10.1016/j.psychsport.2011.12.003 


\section{ACCEPTED MANUSCRIPT}

Niven, K., Totterdell, P., \& Holman, D. (2009). A classification of controlled interpersonal affect regulation strategies. Emotion, 9, 498--509. doi:10.1037/a0015962

Parkinson, B., \& Simons, G. (2012), Worry spreads: Interpersonal transfer of problem-related anxiety, Cognition and Emotion, 26(3), 462--479. doi:10.1080/02699931.2011.651101

Perkins, D., Wilson, G. V., \& Kerr, J. H. (2001). The effects of elevated arousal and mood on maximal strength performance in athletes. Journal of Applied Sport Psychology, 13(3), 239--259. doi:10.1080/104132001753144392

Petrides, K. V., Furnham, A., \& Mavroveli, S. (2007). Trait emotional intelligence: Moving forward in the field of EI. In G. Matthews, M. Zeidner, \& R. Roberts, (Eds.). Emotional intelligence: Knowns and unknowns (Series in Affective Science). Oxford University Press.

Robazza, C., Bortoli, L., \& Hanin, Y. L. (2004). Precompetition emotions, bodily symptoms, and task-specific qualities as predictors of performance in high-level karate athletes. Journal of Applied Sport Psychology, 16, 151-165. doi:10.1080/10413200490437679

Ruiz, M. C., \& Hanin, Y. L. (2011). Perceived impact of anger on performance of skilled karate athletes. Psychology of Sport \& Exercise, 12, 242--249.

doi:10.1016/j.psychsport.2011.01.005

Ruiz, M. C., \& Hanin, Y. L. (2004). Metaphoric description and individualized emotion profiling of performance states in top karate athletes. Journal of Applied Sport Psychology, 16, 258--273. doi:10.1080/10413200490498366 


\section{ACCEPTED MANUSCRIPT}

Russell, J. A. (1980). A circumplex model of affect. Journal of Personality and Social Psychology, 39, 1161--1178.

Tamir, M. (2011). The maturing field of emotion regulation. Emotion Review, 3, 3--7. doi:10.1177/1754073910388685

Tamir, M., Mitchell, C., \& Gross, J. J. (2008). Hedonic and instrumental motives in anger regulation. Psychological Science, 19, 324--328. doi:10.1111/j.1467-9280.2008.02088.x

Terry, P. C. (1995). The efficacy of mood state profiling among elite competitors: A review and synthesis. The Sport Psychologist, 9, 309--324.

Terry, P. C., \& Lane, A. M. (2000). Normative values for the Profile of Mood States for use with athletic samples. Journal of Applied Sport Psychology, 12, 93--109. doi:10.1080/10413200008404215

Terry, P. C., \& Slade, A. (1995). Discriminant capability of psychological state measures in predicting performance outcome in karate competition. Perceptual and Motor Skills, 81, 275--286. doi:10.2466/pms.1995.81.1.275

Thomas, O., Picknell, G., \& Hanton, S. (2011). Recall agreement between actual and retrospective reports of competitive anxiety: A comparison of intensity and frequency dimensions. Journal of Sports Sciences, 29(5), 495--508.

doi:10.1080/02640414.2010.541479

Thomas, P. R., Murphy, S. \& Hardy, L. (1999). Test of Performance Strategies: Development and preliminary validation of a comprehensive measure of athletes' psychological skills. Journal of Sports Sciences, 17, 697--711. doi:10.1080/026404199365560 


\section{ACCEPTED MANUSCRIPT}

Tod, D., Iredale, F., \& Gill, N. (2003). 'Psyching-up' and muscular force production. Sports Medicine, 33(1), 47--58. doi:10.2165/00007256-200333010-00004

Zaki, J., \& Williams, W. C. (2013). Interpersonal emotion regulation. Emotion, 13(5), 803--810. doi:10.1037/a0033839 


\section{ACCEPTED MANUSCRIPT}

Table 1: Athlete participant profiles

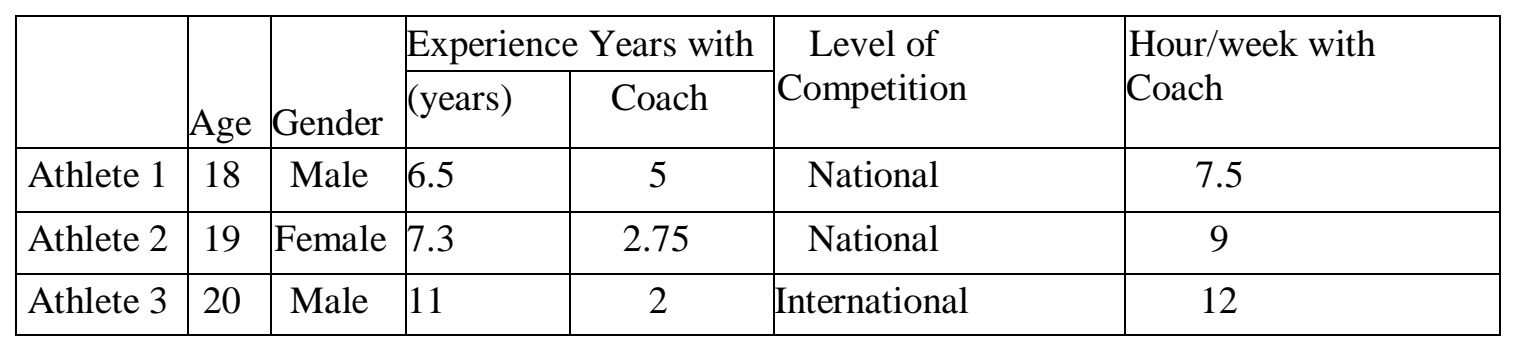




\section{ACCEPTED MANUSCRIPT}

Table 2: Descriptive statistics of time-point recordings; $N=90(\mathrm{~N}=56$ competition; $\mathrm{N}=34$ training)

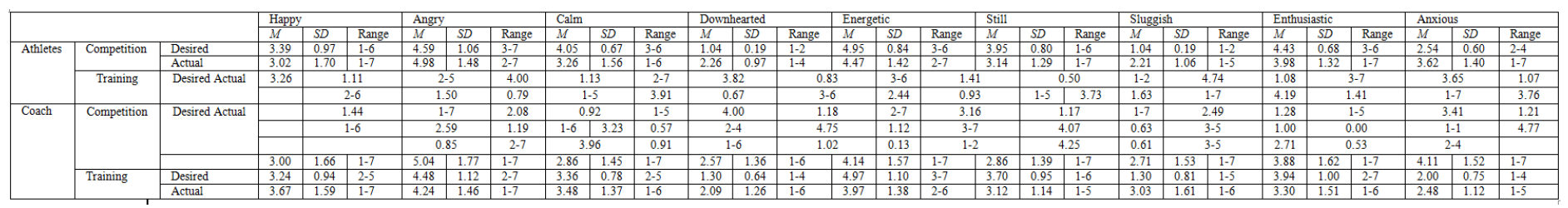




\section{ACCEPTED MANUSCRIPT}

Table 3: Pearson $r$ correlations between emotion congruence and perceived performance

\begin{tabular}{|l|l|l|l|l|l|l|l|l|l|}
\hline & $\begin{array}{l}\text { Happ } \\
\mathrm{y}\end{array}$ & $\begin{array}{l}\text { Angr } \\
\mathrm{y}\end{array}$ & $\begin{array}{l}\text { Cal } \\
\mathrm{m}\end{array}$ & $\begin{array}{l}\text { Downhearte } \\
\mathrm{d}\end{array}$ & $\begin{array}{l}\text { Energeti } \\
\mathrm{c}\end{array}$ & $\begin{array}{l}\text { Still } \\
\mathrm{S}\end{array}$ & $\begin{array}{l}\text { Sluggis } \\
\mathrm{h}\end{array}$ & $\begin{array}{l}\text { Enthusiasti } \\
\mathrm{c}\end{array}$ & $\begin{array}{l}\text { Anxiou } \\
\mathrm{s}\end{array}$ \\
\hline $\begin{array}{l}\text { Athlete } \\
\mathrm{s}\end{array}$ &.$- .52^{*}$ & $-.67^{*}$ & $\begin{array}{l}- \\
.51^{*}\end{array}$ & $-.64^{*}$ & $-.43^{*}$ & $\begin{array}{l}- \\
.34^{*} \\
*\end{array}$ & $\begin{array}{l}-.57^{*} \\
-.41^{*}\end{array}$ & $-.45^{*}$ \\
\hline Coach & $-.54^{*}$ & $-.42^{*}$ & $\begin{array}{l}- \\
.41^{*}\end{array}$ & $-.61^{*}$ & $-.28^{* *}$ & $\begin{array}{l}- \\
.48^{*}\end{array}$ & $-.55^{*}$ & $-.43^{*}$ & $-.41^{*}$ \\
\hline
\end{tabular}

$* p<.001$.

$* * p<.05$

Note. Negative correlations indicate a lower discrepancy between actual and desired emotions. 


\section{ACCEPTED MANUSCRIPT}

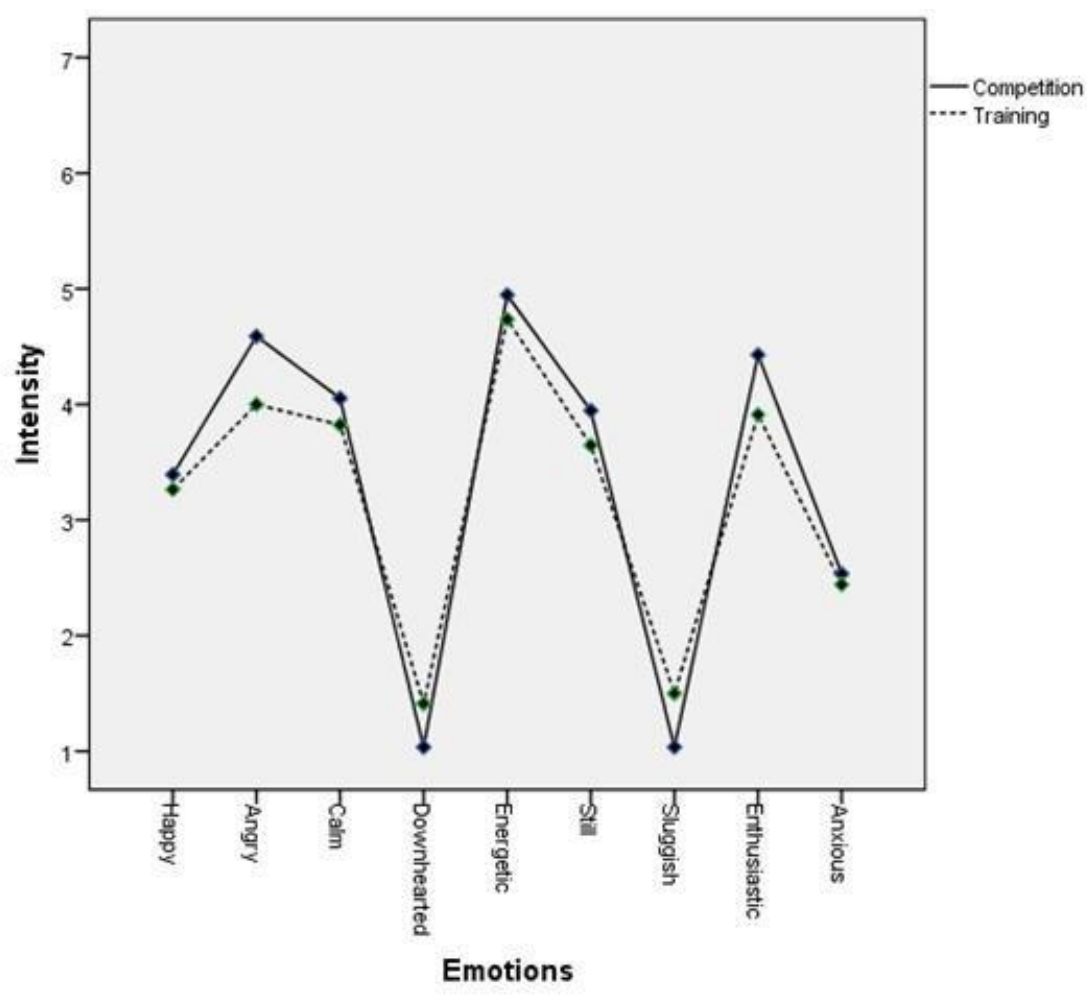

Figure 1: Athlete differences in desired emotions by situation 


\section{ACCEPTED MANUSCRIPT}

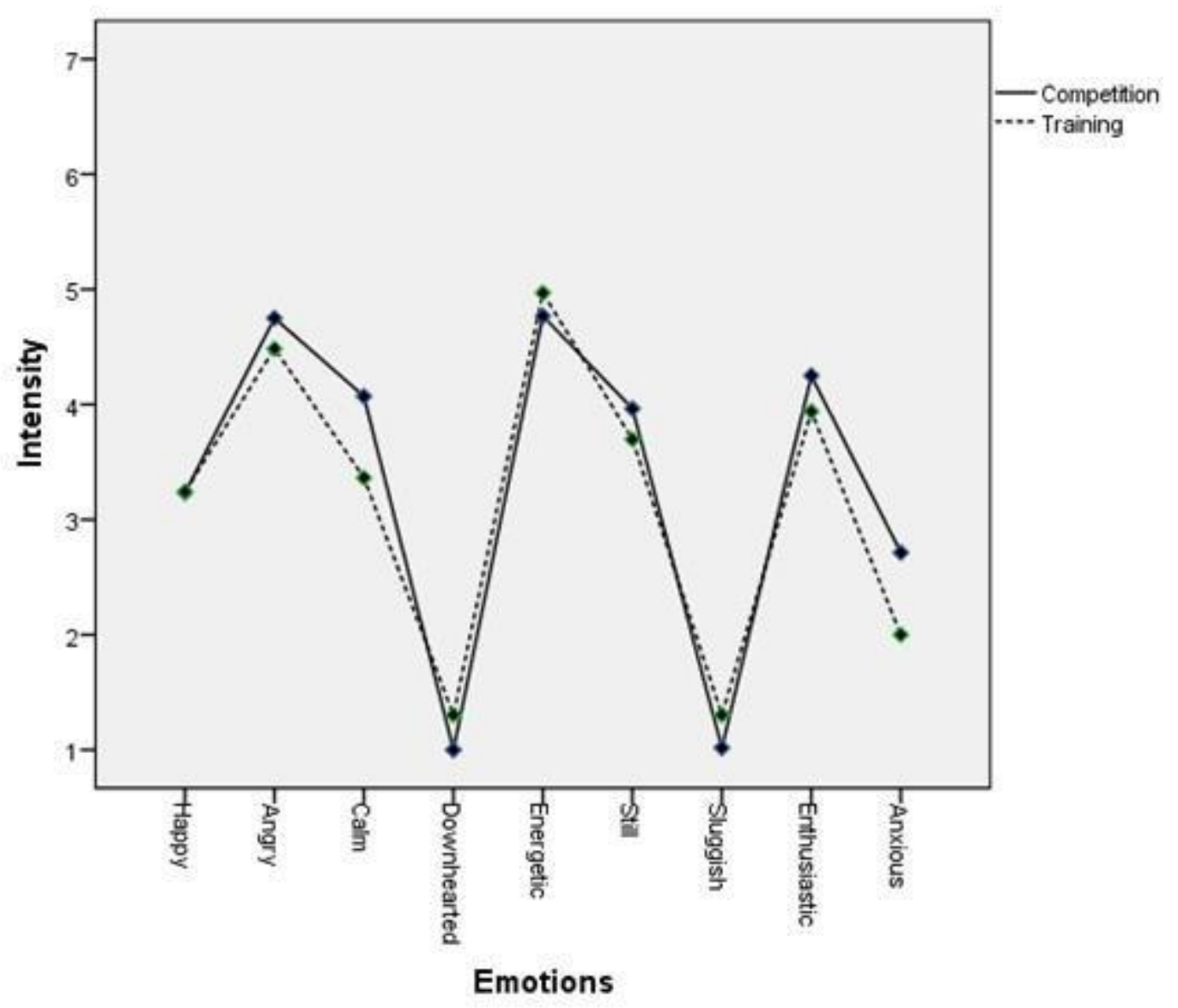

${ }^{26}$ ACCEPTED MANUSCRIPT 


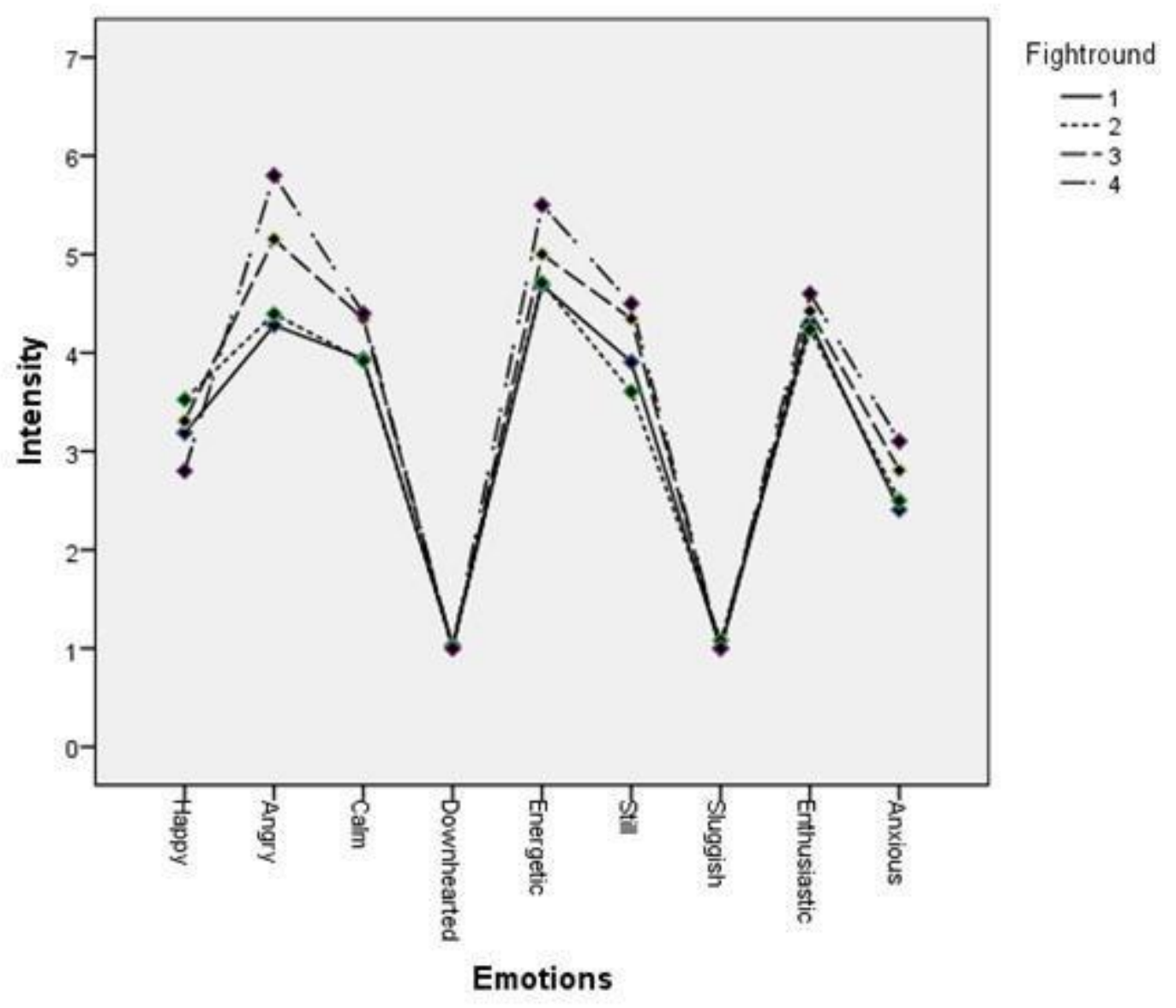

